\author{
ANNALS OF THE NEW YORK ACADEMY OF SCIENCES \\ Issue: Barrett's Esophagus: The 10th OESO World Congress Proceedings
}

\title{
Barrett's esophagus: histology and immunohistology
}

\author{
Hugh Barr, ${ }^{1}$ Melissa P. Upton, ${ }^{2}$ Roy C. Orlando, ${ }^{3}$ David Armstrong, ${ }^{4}$ Michael Vieth, ${ }^{5}$ \\ Helmut Neumann, ${ }^{6}$ Cord Langner, ${ }^{7}$ Elizabeth L. Wiley, ${ }^{8}$ Kiron M. Das, ${ }^{9}$ \\ Octavia E. Pickett-Blakely, ${ }^{10}$ Manisha Bajpai, ${ }^{9}$ Peter S. Amenta, ${ }^{9}$ Ana Bennett, ${ }^{11}$ \\ James J. Going, ${ }^{12}$ Mamoun Younes, ${ }^{13}$ Helen H. Wang, ${ }^{14}$ Antonio Taddei, ${ }^{15}$ Giancarlo Freschi, ${ }^{15}$ \\ Maria Novella Ringressi, ${ }^{15}$ Duccio Rossi Degli'Innocenti, ${ }^{16}$ Francesca Castiglione, ${ }^{16}$ \\ and Paolo Bechi ${ }^{15}$ \\ ${ }^{1}$ Cranfield University, Gloucestershire Royal Hospital, Gloucester, United Kingdom. ${ }^{2}$ University of Washington Medical Center, \\ Seattle, Washington. ${ }^{3}$ University of North Carolina School of Medicine at Chapel Hill, Chapel Hill, North Carolina. ${ }^{4}$ Division of \\ Gastroenterology and Farncombe Family Digestive Health Research Institute, McMaster University Medical Centre, Hamilton, \\ Ontario, Canada. ${ }^{5}$ Institute of Pathology, Klinikum Bayreuth, Bayreuth, Germany. ${ }^{6}$ Medical Clinic, University of Erlangen, \\ Erlangen, Germany. ${ }^{7}$ Institute of Pathology, Medical University Graz, Graz, Austria. ${ }^{8}$ Division of Surgical Pathology, \\ Department of Pathology, University of Illinois Medical Center, Chicago, Illinois. ${ }^{9}$ UMDNJ-Robert Wood Johnson Medical \\ School, New Brunswick, New Jersey. ${ }^{10} \mathrm{Hospital}$ University of Pennsylvania, Philadelphia, Pennsylvania. ${ }^{11}$ Department of \\ Anatomic Pathology, Cleveland Clinic Main Campus, Cleveland, Ohio. ${ }^{12}$ Institute of Cancer Sciences, University of Glasgow \\ and Department of Pathology, Glasgow Royal Infirmary, Glasgow, Scotland, United Kingdom. ${ }^{13}$ Department of Pathology and \\ Immunology, Baylor College of Medicine, Houston, Texas. ${ }^{14}$ Department of Pathology, Beth Israel Deaconess Medical Center, \\ Harvard Medical School, Boston, Massachusetts. ${ }^{15}$ Unit of Surgery, Department of Medical and Surgical Critical Care, \\ University of Florence, Italy. ${ }^{16}$ Unit of Human Pathology, Department of Medical and Surgical Critical Care, University of \\ Florence, Italy
}

The following on histology and immunohistology of Barrett's esophagus (BE) includes commentaries on the various difficulties remaining in reaching a consensus on the definition of $\mathrm{BE}$; the difficulties in the characterization of intestinal and cardiac mucosa, and in the role of submucosal glands in the development of BE; the importance of a new monoclonal antibody to recognize esophageal intestinal mucosa; the importance of pseudo goblet cells; the best techniques for the endoscopic detection of Barrett's epithelium; and the biomarkers for identification of patients predisposed to the development of BE.

Keywords: ACG guidelines; BSG guidelines; epithelium; intestinal metaplasia; esophageal microanatomy; cytokeratin 7; cytokeratin 20; CDX2; reflux esophagitis; submucosal glands; Montreal Working Group; Prague criteria; cardiac mucosa; oxyntic cells; goblet cells; gastroesophageal junction; adenocarcinoma; pseudogoblet cells; esophageal glands; four-quadrant biopsies; MUC2; villin; Das-1; immunohistochemistry

\section{Concise summaries}

- There are still several challenges to achieving consensus on the definition of Barrett's esophagus (BE). The element of proximal extension must be based on an accurate, reproducible endoscopic identification of the gastroesophageal junction (GEJ). All metaplasia in the columnar lined esophagus may already be partway on the path to cancer. In addition, the progression to cancer of patients with no goblet cells and goblet cells appears to be similar. Intestinal metaplasia (IM) of both the esophagus and the cardia share many features, with respect to expression of certain antigens.

- There is currently no immunohistochemical marker that is specific to assist in defining the anatomic site of the biopsy or resection sample.

- Despite experimental observations on animals suggesting that $\mathrm{BE}$ can develop from an alternative source in an esophageal environment made noxious by reflux, they does not preclude the cell of origin for $\mathrm{BE}$ in humans being derived from the ducts of the submucosal glands (SMGs). 
- There is not yet consensus on the definition of BE. The element of proximal extension must be based on an accurate and reproducible endoscopic identification of the GEJ. Cardiac mucosa can be abnormal and metaplastic and can progress to dysplasia and adenocarcinoma, but the frequency is unknown.

- The type of GEJ adenocarcinomas and the male:female ratio are different from those with a profile of Barrett's mucosa, thus suggesting differences in the mechanism of cancer development and the role IM as a marker of cancer risk.

- Metaplasia of colonic phenotype may occur at the distal esophagus in the absence of histological BE and may progress to BE. Therefore, Das-1 monoclonal antibody reactivity may be a useful marker in the identification of BE at an early stage when chemopreventive strategies may be effective.

- It is essential for the pathologist to be aware of the presence of "pseudogoblet" cells or gob- let mimickers that, in the absence of true intestinal-type goblet cells, do not seem to have a predictive value in neoplastic progression. Systematic biopsy appears to be a sound method for identifying IM defined by the presence of goblet cells. However, if the definition of $\mathrm{BE}$ is revised to include glandular mucosae without goblet cells, then less comprehensive biopsy strategies may be as effective in establishing the diagnosis, and detection of dysplasia will be even more important.

- The use of biomarkers may help confirm the diagnosis. Problems arise, however, if these markers are applied indiscriminately to all esophageal or esophagogastric junction biopsies endoscopically suspected of being BE.

- Although CDX2 and MUC-2 are both definite markers of IM, they cannot be used to identify patients at risk of BE because they do not seem to be expressed in any of the earlier steps of reflux disease.

\section{Is the histological presence of IM to defiantly included in the definition of BE?}

Hugh Barr

hugh.barr@glos.nhs.uk

The diagnosis of $\mathrm{BE}$ is dependent on endoscopic and histopathological criteria. The identification of patients at risk of neoplastic progression with "bad Barrett's" is vital. Currently, the guidelines produced by the American College of Gastroenterology ${ }^{1}$ and the British Society of Gastroenterology differ. ${ }^{2}$

The American College of Gastroenterology definition states that the change in the distal esophageal epithelium of any length that can be recognized as columnar type mucosa at endoscopy and is confirmed to have IM by biopsy of the tubular esophagus. These guidelines recognize that the yield of IM decreases as the segment of columnar lining shortens and fewer biopsies are taken. Repeat endoscopy and biopsy are often necessary to establish the presence of IM. Very few patients with long segment Barrett's have no goblet cells on biopsy. It is also common not to see these cells in patients with segments less than $1 \mathrm{~cm}$ in length. It is also clear that intestinalization is heterogeneous and focal. ${ }^{1}$
The British Society of Gastroenterology definition states that any portion of the normal squamous lining replaced by a metaplastic columnar epithelium that is visible macroscopically. To make a positive diagnosis of a segment of columnar metaplasia of any length, it must be visible endoscopically above the esophago-gastric junction and confirmed, corroborated, or in keeping with histology:

(i) Confirmed: native esophageal structures are present with juxtaposition to metaplastic glandular mucosa, whether intestinalized or not;

(ii) Corroborative: this could potentially still represent incomplete IM in the stomach;

(iii) In keeping: gastric type mucosa of either fundic or cardiac type; and

(iv) No evidence: esophageal type squamous mucosa with no evidence of glandular epithelium. ${ }^{2}$

Liu et al. $^{3}$ have shown that of 68 patients with columnar metaplasia, 22 patients had no goblet cells identified, and 46 contained goblet cells in their biopsies. In both groups, there were chromosomal and genetic instability, and DNA content abnormalities. There were no significant differences between these cellular DNA abnormalities between the 
Table 1. Progression to cancer of patients with intestinal metaplasia or not on biopsy

\begin{tabular}{lcc}
\hline & $\begin{array}{c}\text { Number of } \\
\text { patients }\end{array}$ & $\begin{array}{c}\text { Cancer } \\
\text { progression }\end{array}$ \\
\hline $\begin{array}{l}\text { Kelty et al. } \\
\quad \text { 12 year follow-up }\end{array}$ & & \\
$\quad$ Intestinal metaplasia & 379 & $4.5 \%$ \\
$\quad$ No intestinal metaplasia & 309 & $3.6 \%$ \\
$\begin{array}{l}\text { Gatenby et al. } \\
\text { Registry data }\end{array}$ & & \\
$\quad$ Intestinal metaplasia & 612 & $3.1 \%$ \\
$\quad$ No intestinal metaplasia & 322 & $3.2 \%$ \\
\hline
\end{tabular}

two groups. Both were significantly different from gastric controls. Thus, all metaplasia in the columnar-lined esophagus may already be part way on the path to cancer. In addition, the progression to cancer of patients with no goblet cells and goblet cells appears to be similar (Table 1$).^{4,5}$

It appears that all columnar metaplasia in the distal esophagus has neoplastic potential. Guidelines will need to be formulated in the context with this new knowledge and guidelines should be harmonized internationally.

\section{Can IM in the esophagus be reliably distinguished from IM in cardiac mucosa?}

Melissa P. Upton

mupton@u.washington.edu

Can IM in the esophagus be reliably distinguished from IM in cardiac mucosa? The answer is sometimes, but not always, for the following reasons.

The precise site where the esophagus ends and stomach begins cannot always be determined endoscopically or histologically. There is controversy regarding how best to identify the GEJ at endoscopy. In Japan, the preference is to use the palisade vessels as the landmark, but this is not reliable in Western series, which may reflect differences in body habitus of the patients or in endoscopic technique. The Prague criteria use the reference point of the proximal extent of the rugal folds, but there are challenges in interpretation, especially in ultra-short segment $\mathrm{BE}$, due to irregularity of the squamocolumnar junction and the motion of the junction in real time in a living patient. Thus, endoscopic biopsy specimens are provided to pathologists with, at best, "estimates" of location when taken from the GEJ or distal esophagus.

\section{What microanatomic features can define the location of IM detected in biopsy and endoscopic mucosal resection samples?}

Specific microanatomic features are seen in the esophagus but not in the stomach. These include SMGs and their ducts, squamous epithelium, and duplication of the muscularis mucosae. ${ }^{6}$ Depending on sampling, identification of these structures on histology permits the pathologist to locate the specimen as esophageal. Other histologic features more often seen in biopsies from esophagus include multilayered epithelium, the presence of hybrid glands with IM at the mucosal surface and other morphology below, crypt disarray, incomplete IM, and extensive IM. When a biopsy sample has more than one of these features, there is increased sensitivity and sensitivity to predict that the biopsy is from the esophagus; when four to five of these features are seen, the sensitivity and specificity of assigning location as esophageal are $85 \%$ and 95\%, respectively. ${ }^{7}$

\section{Is there a background of helicobacter pylori (HP) gastritis?}

Biopsies from gastric antrum and body are essential to evaluate the context of background gastric histology. "Short-segment" IM at the GEJ in a setting of intestinalized pan-gastritis and HP infection is likely HP-related cardiac IM rather than related to chronic reflux, but some patients with HP gastritis may also have reflux esophagitis. Helicobacter organisms may be seen on hematoxylin and eosin (H\&E) or special stains but might not be detected in chronic and extensively intestinalized cases.

\section{Is there a difference in expression of cytokines, comparing esophageal IM with cardia IM?}

Ormsby and associates at the Cleveland Clinic Foundation studied 31 surgical resection or biopsy specimens from long segment $\mathrm{BE}$ and 13 gastric cardia biopsies with IM, obtained by retroflexing the endoscope within $5 \mathrm{~mm}$ of a normal appearing squamocolumnar junction. ${ }^{8}$ They identified a "BE specific staining pattern" of strong expression of Cytokeratin 7 by surface and glandular epithelium, along with weak superficial CK20 staining. This BE pattern was not seen in any of the gastric IM specimens. ${ }^{8}$ However, this staining pattern has not been 
consistently reproduced in other hands. Glickman and associates reported in 2001 a study of cases of short segment BE, long segment BE, IM at GEJ, $\mathrm{IM}$ in gastric antrum in HP gastritis, normal nonmetaplastic GEJ, and normal antrum. The Barrett'stype CK pattern defined by the Ormsby group was seen in LSBE, SSBE, and IMGEJ, and in 14\% of IM in gastric antrum in HP cases in their hands. ElZimaity et al. reported (also in 2001) that eight of 23 patients with cardia IM had the Ormsby "BE pattern.” In a review summarizing results of 16 studies with 46 comparisons using cytokeratin staining, approximately half of the studies reported results that supported the Ormsby finding, but the other half rejected the specificity of CK7/20 staining to separate IM of BE from IM of cardia. ${ }^{9}$ Consequently, given the variability of reported results, pathologists in most institutions are not applying these stains in clinical practice to differentiate esophageal IM from cardiac IM.

\section{Are there other markers that can assist in differentiating esophageal IM from cardia IM?}

Das-1 antibody recognizes goblet cells in colonic mucosa, and it can be seen in mucosa of BE even without goblet cells. It is an interesting marker that may be an early sign of IM, but it is also seen in cardiac glands with IM. CDX2 (caudal-type homeobox 2) is a master switch for intestinalization that is expressed in BE with and without goblet cells. It appears to be an early marker of intestinalization that can be detected before intestinal features, such as goblet cells or production of acidic mucin, can be seen on routine histology; however, it is also expressed in gastric IM. Antibodies against mucins (MUCs), Hepar-1, CD-10 may be useful for identification of IM, but they do not improve detection over histology, and they do not appear to assist in discerning if a biopsy is from the esophagus or the cardia. There are many individual studies of various immunohistochemical markers, summarized in several recent reviews, and none appears specific for differentiating esophageal IM from cardia IM. ${ }^{10}$

In summary, in 2010, IM of both the esophagus and the cardia share many features, with respect to expression of certain antigens. There is currently no immunohistochemical marker that is specific to assist in defining the anatomic site of the biopsy or resection sample. Careful histologic examination, with attention to certain microanatomic fea- tures, appears to be the most sensitive and specific method to determine the location of biopsies, and clear endoscopic-pathologic correlation remains the gold standard of clinical practice.

\section{Is there evidence for a role of the esophageal SMGs in the origin of BE?}

Roy C. Orlando

rorlando@med.unc.edu

$\mathrm{BE}$ is an esophageal lesion that develops in the distal esophagus of patients with reflux esophagitis. In this respect, it is likely a form of adaptive protection because its biology appears to provide greater protection against acid injury than does native esophageal stratified squamous epithelium. ${ }^{11}$ Among the data that support this scenario are the greater frequency of the lesion in subjects with gastroesophageal reflux disease (GERD) than in the general population without GERD, its emergence in distal esophagus in those with reflux esophagitis and in the proximal esophageal segment following esophagectomy in those with esophagogastrostomy, and documentation in animal models of reflux esophagitis showing replacement of eroded squamous epithelium with Barrett's specialized columnar epithelium. ${ }^{12}$

The origin of the cell(s) that give rise to $\mathrm{BE}$ is unknown. However, since the characteristic morphology of BE requires the presence of goblet cells, and goblet cells are not normally present in any tissue adjacent to esophageal epithelium, the cell of origin must be pluripotential and capable of adapting to the noxious environment. The candidate tissues from which the pluripotential cell is derived include (a) gastric cardiac epithelium; (b) esophageal stratified squamous epithelium; and (c) the epithelium lining the ducts of the esophageal SMGs.

The case for the cell of origin in BE being from the ducts of the esophageal SMGs include the following:

1. Location: the ducts of the SMGs are widely distributed along the length of the human esophagus, as is evident by their visualization when dilated in patients with intramural pseudodiverticulosis;

2. Morphology: the morphology of the ducts of the SMGs varies from simple columnar in the lower two-third nearest the acini to stratified squamous in the upper one-third nearest the 
lumen which indicates that it has the intrinsic capacity for generation of both squamous and columnar phenotypes; and ${ }^{13}$

3. Observation: experimental models of reflux esophagitis in the canine, an animal whose esophagus contain SMGs, have shown continuity between the ducts of the SMGs and the surface generation of Barrett's specialized columnar epithelium. ${ }^{14}$ Moreover the generation of $\mathrm{BE}$ in this model occurs in the lower esophagus even when the damaged/resected areas are not in continuity with gastric mucosa. ${ }^{15}$

The most challenging observation that argues against the cell of origin in BE being derived from the ducts of the esophageal SMGs is that experimental models of reflux esophagitis in the rat, an animal whose esophagus is devoid of SMGs, have also been shown to develop Barrett's specialized columnar epithelium. While this observations suggests that BE can develop from an alternative source in an esophageal environment made noxious by reflux, it does not preclude the cell of origin for BE in humans being derived from the ducts of the SMGs.

\section{Is there a consensus on the definition of $B E$ ?}

David Armstrong armstro@mcmaster.ca

A diagnosis of $\mathrm{BE}$ is predicated on the presence of metaplastic columnar epithelium, extending proximally from the GEJ, leading to replacement of the original esophageal squamous epithelium. ${ }^{1}$

The criterion that the columnar epithelium should extend proximally from the GEJ, necessarily excludes columnar islands found in the proximal esophagus but it should not exclude islands of columnar epithelium located in the distal esophagus. However, although there is good general agreement on the principle that BE represents columnar metaplasia, a precise definition remains tantalizing elusive. ${ }^{1}$ The diagnosis of $\mathrm{BE}$ requires the endoscopic identification of an abnormal area of epithelium in the distal esophagus, but it is generally agreed that the diagnosis should then be confirmed histologically.

On this basis, the Montreal working group proposed the term "endoscopically suspected esophageal metaplasia" (ESEM) to describe endo- scopic findings consistent with BE that await histological evaluation. ${ }^{16}$ The American College of Gastroenterology guidelines state that " $\mathrm{BE}$ is a change in the distal esophageal epithelium of any length that can be recognized as columnar type mucosa at endoscopy and is confirmed to have IM by biopsy of the tubular esophagus."

However, there is, by no means, universal agreement that IM is a prerequisite for the diagnosis of $\mathrm{BE},{ }^{1}$ and, for this reason, the Montreal working group proposed that $\mathrm{BE}$ be diagnosed when biopsies from ESEM show columnar epithelium with the rider that the presence or absence of intestinal-type metaplasia should also be specified. ${ }^{16}$

There are several challenges to achieving consensus on the definition of BE. One major challenge is that it can be difficult to locate the GEJ precisely; if this cannot be achieved, it will be difficult to know whether any columnar epithelium has, indeed, been replaced by squamous epithelium. Another major challenge arises from uncertainty as to the malignant potential of different types of columnar epithelium; specifically, there is no consensus as to whether the absence of intestinal-type metaplasia is sufficient to conclude that there is negligible risk of developing esophageal adenocarcinoma. ${ }^{1}$ The final major challenge arises because it is clear that there can be marked disparity between endoscopic findings and histological findings. ${ }^{16}$

The endoscopic detection of ESEM and a precise description that includes a standardized measure of its endoscopic extent ${ }^{16}$ requires recognition of the squamocolumnar junction (SCJ) and the GEJ as well as their location, for example, in relation to the distance from the incisors or the dental arcade. The importance of accurate and reproducible endoscopic identification of the GEJ was acknowledged in the development of the Prague C\&M Criteria. ${ }^{17}$ The proximal limit of the gastric folds, the distal esophageal pinch (attributable to the lower esophageal sphincter), and the distal limit of the esophageal palisade vessels ${ }^{18}$ were all considered as potential landmarks of the GEJ. In the validation of the Prague Criteria, the reliability coefficients of 0.88 and 0.78 , respectively were reported for identification of the proximal limit of the gastric folds and the pinch in the distal esophagus. ${ }^{17}$ This excellent inter observer agreement on identification of the GEJ was not, however, matched in a similar study that reported markedly lower kappa values for 
identification of the palisade vessels (0.16) and the tops of the gastric folds (0.12: pre-education; 0.35 : post-education). ${ }^{18}$

For patients with columnar metaplasia, the risk of esophageal adenocarcinoma is greater for those who have intestinal-type metaplasia. ${ }^{1}$ However, the detection of intestinal-type metaplasia is dependent upon the extent of the ESEM and on the number of biopsies taken; it has been proposed that eight biopsies may be needed to assess adequately for intestinal-type metaplasia. ${ }^{1}$ Thus, the absence of documented intestinal-type metaplasia may not be sufficient to exclude a diagnosis of BE. Obtaining adequate numbers of biopsies and ensuring that the biopsies are acquired from the area of interest can also be a challenge, particularly if the area of interest is small, as in short segment BE. For example, less than one third of biopsies obtained in a study of patients with reflux disease showed histological features consistent with the area that had been targeted. ${ }^{19}$ This, along with regional heterogeneity in the columnar epithelium, may explain the discrepancies, noted previously, between endoscopic and histological findings in patients with ESEM. ${ }^{16}$

In conclusion, there is not yet consensus on the definition of $\mathrm{BE}$ although there is, perhaps, agreement that the term, BE, describes columnar metaplasia, extending proximally from the GEJ to replace esophageal squamous epithelium. ${ }^{16}$ Histological confirmation that the abnormal endoscopic appearances are, indeed, indicative of columnar metaplasia is consistent with this definition with the caveat that the element of proximal extension must be based on an accurate, reproducible endoscopic identification of the GEJ.

The Prague C\&M criteria, currently, provide the best-validated GEJ landmarks, although they are not infallible; ${ }^{17}$ however, inter-observer agreement studies have not, to date, provided adequate support for the use of other landmarks. ${ }^{18}$ The biggest barrier to achieving consensus on the definition of $\mathrm{BE}$ relates to the risk of esophageal adenocarcinoma. If $\mathrm{BE}$ is defined as the replacement of esophageal squamous epithelium by metaplastic columnar epithelium, it should not be difficult to achieve consensus on the definition although the diagnosis may still be difficult in individuals with very small areas of columnar metaplasia. If, however, the definition of $\mathrm{BE}$ encompasses the malignant potential attributable to the metaplasia, it will be very difficult to achieve consensus. The number and location of biopsies required for an accurate assessment of the cancer risk is unknown; similarly, the risks attributable to different types of metaplasia are unknown as are the effects of treatment, age, environmental, and genetic factors. Furthermore, in practice, the diagnosis is influenced by social factors such as the patient's financial or health insurance status. ${ }^{1}$ Clearly, BE is important because of the risk of malignancy; however, if it is defined by this risk, it will remain very difficult, if not impossible, to achieve consensus on the definition of BE.

\section{Is cardia mucosa always abnormal and of metaplastic origin? Can it progress to dysplasia and adenocarcinoma?}

Michael Vieth, Helmut Neumann, and

Cord Langner

Vieth.LKPathol@uni-bayreuth.de

Cardia mucosa is rather ill-defined. It consists of foveolar epithelium and mucous glands but can contain oxyntic cells as well and differs from pure oxyntic mucosa by the notion that cardia epithelium appears rather atrophic. Since no strict and widely accepted histopathological definition of cardia mucosa exists, one has to accept cardia mucosa as being kind of a transitional epithelium between the squamous epithelium of the distal esophagus and the columnar epithelium of the proximal stomach, which is present in virtually every individual. Data available are weak also due to the fact that there is no precise definition in terms of gross anatomy. The mean length reported in the literature varies between $0.314 \mathrm{~mm}$ and $1.8 \mathrm{~mm},{ }^{20,21}$ probably depending on the selected population. Of note, cardia mucosa may not be detected in some individuals, but in general it is believed to lengthen with age and can be found in fetuses, kids, toddlers, and adults with and without reflux disease. According to experimental data, development of a cardia-like mucosa can be induced by reflux promoting operation in baboons. Moreover, cardia mucosa was documented to occur proximal to the anastomosis after cardia resection in the majority of individuals within a follow-up period of 3-88 months. ${ }^{22}$ In this study the length varied between 0.3 and $7 \mathrm{~cm}$. 


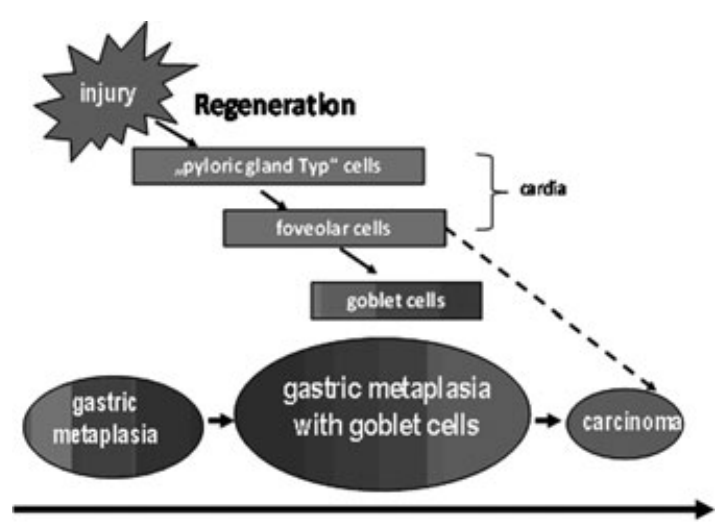

Gut regenerative cell lineage

Figure 1. Gut regenerative cell lineage on morphogenesis of columnar metaplasia within the distal esophagus, modified after Hattori et al. ${ }^{23}$

The concept of gut regenerative cell lineage includes stem cell driven regeneration induced by epithelial injury and followed by the appearance of deep gastric mucous glands (pyloric type cells) and foveolar type of cells (gastric surface epithelium). Together, these two components are nothing else than cardia-like mucosa. Later on, goblet cells may $\operatorname{appear}^{23}$ (Fig. 1).

Recently, a thorough literature review demonstrated that not all Barrett adenocarcinomas showed goblet cell-containing epithelium right next to the tumor, but cardia-like epithelium was observed in a considerable amount of cases. ${ }^{24}$ There was no significant association with the size of the tumor but with the length of the Barrett's segment. In addition, these columnar segments without goblet cells and without neoplasia show molecular abnormalities similar to goblet cell-containing epithelium, ${ }^{25}$ indicating that individuals without goblet cells in a columnar segment may have a risk of malignant transformation.

Thus, available data are confusing:

- On the one hand, it is possible that cardia epithelium within the proximal stomach (however that is defined) represents a physiological condition; it may even become longer with age, indicating adaptive rather than metaplastic change.

- On the other, cardia-like epithelium proximal to the gastro-esophageal junction (however that is defined) has to be regarded a meta- plastic condition with risk of malignant transformation (that is much lower than in cases with goblet cells as it looks at the moment.) Adopting data on the carcinogenic role of IM in the stomach to the esophagus, the risk of malignant transformation of columnar metaplasia (in the distal esophagus) with goblet cells may be at least five to six times higher compared to cases with columnar metaplasia lacking goblet cells, but in fact, we do not know.

Clinical implications are not clear at the moment. In particular, we do not know what to do with individuals that show endoscopic columnarlined esophagus but no goblet cells. An inflationary increase of the diagnosis "BE" is possible.

In conclusion, the questions addressed above can be answered as follows:

- Yes, cardia mucosa can be abnormal and metaplastic, but not in all cases (depending also on the definition of the gastro-esophageal junction); and

- Yes, cardia mucosa can progress to dysplasia and adenocarcinoma, but the frequency is unknown.

\section{What is the significance of microscopic foci of specialized IM at the GEJ?}

Elizabeth L. Wiley

ewiley@uic.edu.

IM is a known risk factor for development of adenocarcinoma (AdCa) of distal esophagus, distal stomach, and gallbladder. The degree of risk of AdCa developing in the setting of IM of the esophagus varies with the length of esophagus that has undergone columnar metaplasia. ${ }^{26}$ Long segment BE has greater risk of AdCa than short segment. Stein ${ }^{26}$ suggests that ultra-short segment Barrett's or small foci of IM at the GEJ, may carry an elevated but lesser risk of carcinoma than either short segment and long segment Barrett's mucosa.

Case reports, such as Gangarsosa's report of two patients with foci of IM at the GEJ in which one developed invasive carcinoma in follow-up, indicate that increased risk of development of AdCa may exist for patients with small foci of IM at the GEJ. ${ }^{27}$ Siewert, ${ }^{28}$ in his review of 1002 patients with AdCa of the GEJ found differences in the 
patient population and tumor type by precise tumor location. AdCa of the distal esophagus (DE) had coexisting IM in $75 \%$, and nearly $80 \%$ of tumors had intestinal growth pattern. Only $10 \%$ of tumors arising at the GEJ had coexisting IM and more than half had diffuse type AdCa; but since only $14 \%$ of GEJ tumors were pT1 tumors, any preexisting foci of IM may have been overrun by the carcinomas. There was also a difference in the patient population. There was a 9:1 male to female ratio for DE AdCa, whereas GEJ tumors had a 5.4:1 male to female ratio.

Tytgat, ${ }^{29}$ in his review of several studies, found a 6 to $24 \%$ incidence of IM at the GEJ in symptomatic patients undergoing upper gastrointestinal endoscopy. In the same group of studies, short segment BE had a slightly lower incidence (2-12\%). Although Tytgat ${ }^{29}$ suggests that the incidence of IM at the GEJ may be higher in the general population, the exact difference has not been established. At the author's university medical center, a large group of patients undergo upper endoscopy for complaints other than GERD. Review of pathology for Quality Assurance showed that in a one-year period, 2\% of patients without complaints of gastritis, GERD, or history of Barrett's had a new diagnosis of IM on biopsy of the DE, and IM was found in $9 \%$ of those who were biopsied at the GEJ. For comparison, $5 \%$ of $\mathrm{DE}$, and $7 \%$ of GEJ biopsies of patients with symptoms of GERD had newly diagnosed IM, and $4 \%$ of DE and $12 \%$ of GEJ biopsies of patients with symptoms of gastritis were diagnosed with IM. Eleven AdCas were diagnosed during the same one-year period, only two of which were associated with a history of Barrett's, and none of the remaining nine had presenting complaints of GERD or gastritis.

In summary, there is a low incidence of IM in the distal esophagus and at the GEJ junction. This incidence varies with symptoms; patients with GERD have a higher incidence of IM in the DE, whereas patients without symptoms of GERD have a higher incidence of IM at the GEJ. Indirect evidence shows an elevated risk of AdCa for patients with IM at the GEJ, but the degree of elevation of risk is unknown. The type of GEJ AdCa and the male to female ratio are different than those with a profile of Barrett's mucosa; ${ }^{2}$ this suggests differences in the mechanism of cancer development and the role IM as a marker of cancer risk.

\section{Is the monoclonal antibody, mAb Das-1 likely to help in early recognition of IM of the esophagus?}

Kiron M. Das, Octavia E. Pickett-Blakely, Manisha Bajpai, and Peter S. Amenta

daskm@umdnj.edu

Adenocarcinoma of the esophagus (EAC) has the highest rate of increase among all cancers in the U.S. and in the Western World. The incidence has increased approximately $400 \%$ over the last 25 years. Barrett's epithelium, a specialized columnar metaplasia of the distal esophagus/gastro-esophageal junction (GEJ) from chronic GERD, is a precursor to EAC.

Chronic gastritis from $\mathrm{H}$. Pylori leads to gastric intestinal metaplasia (GIM), which predisposes to gastric cancer, which is a leading cause of cancerrelated deaths in Asian countries. There appears to be a special phenotype known as incomplete or colonic phenotype (also known as Type II or Type III) that is strongly associated with Barrett's epithelium/EAC and GIM/gastric carcinoma. ${ }^{30,31}$ Early detection of Barrett's epithelium and GIM is essential to identify high risk patients with chronic GERD and chronic gastritis to institute appropriate surveillance and treatment.

We developed a monoclonal antibody named mAb Das-1 (also called 7E12H12, IgM isotype) that reacts with the colonic epithelium but not with any other gastrointestinal tract epithelium; including columnar epithelium of small intestine and stomach and squamous epithelium of the esophagus (Fig. 2) ${ }^{32}$ However, mAb Das-1 reacts with Barrett's epithelium and adenocarcinoma arising from Barrett's epithelium with 95\% sensitivity and $100 \%$ specificity (Fig. 2). ${ }^{30}$ It does not react with normal esophageal or gastro-esophageal junction mucosa. This has been confirmed by three independent groups of investigators ${ }^{4}$ who reported a 90 $100 \%$ sensitivity and specificity of mAb Das- 1 in the detection of Barrett's epithelium. Subsequently, we demonstrated that mAb Das-1 can detect metaplasia before the appearance of histological Barrett's epithelium suggesting the existence of a "Pre-Barrett's" stage.

IM of the stomach can be divided into complete or small intestinal and incomplete or colonic type (Type II or III) based on the staining pattern with alcian blue/high iron diamine $(\mathrm{AB} / \mathrm{HID})$ and 

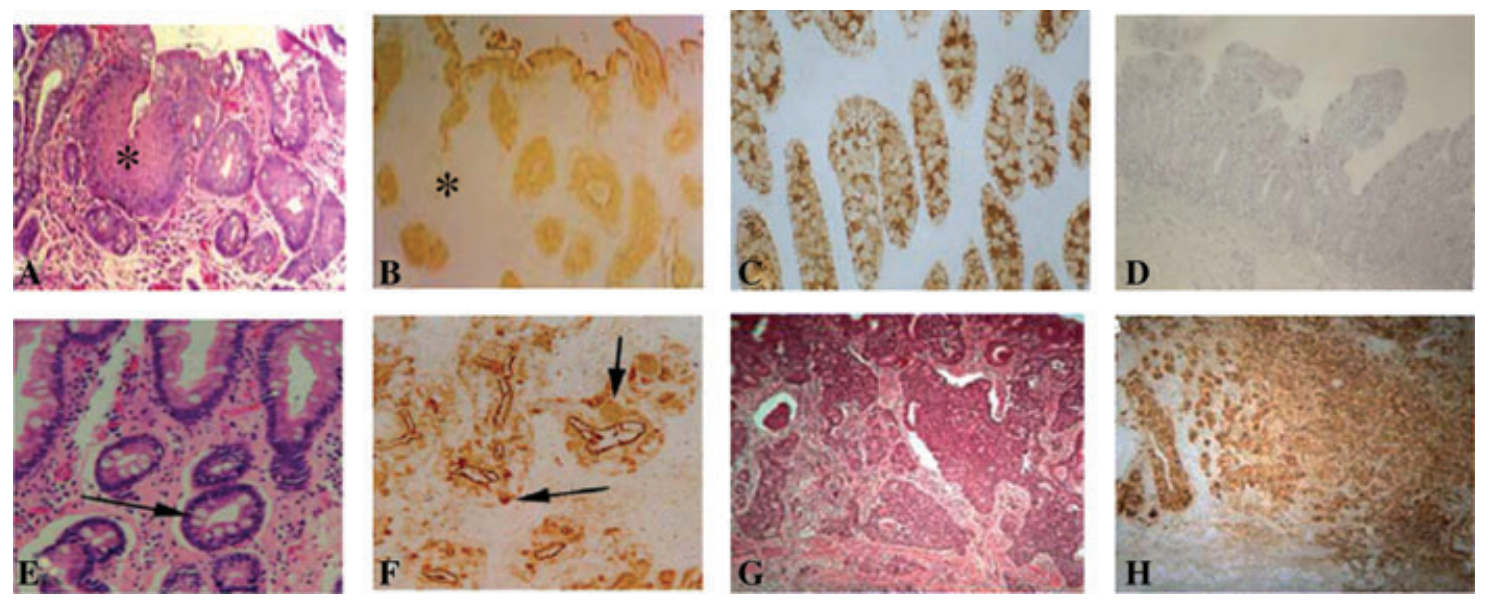

Figure 2. (A) and (B) are serial sections of the biopsy specimen from a patient with BE. (A) H\&E stain showing squamo-columnar junctional mucosa from the EGJ with columnar metaplasia with presence of goblet cells. (B) mAb Das-1 reactivity is present in all the glands, including both goblet and nongoblet cells. Squamous epithelium is identified by $\left(^{*}\right)$ that did not stain with mAb Das-1. (C) and (D) show immunoperoxidase staining of colon (C) and small intestine (D), respectively, as positive and negative control for mAb Das-1. mAb Das-1 reactivity is restricted to colon epithelium, both goblet and absorptive cells. Small-intestinal epithelium did not react with $\mathrm{mAb}$ Das-1. Serial sections of formalin fixed paraffin embedded biopsy tissue from a patient with gastric intestinal metaplasia (GIM) without carcinoma (E \& F) and another patient with gastric carcinoma (G and H). Hematoxylin-eosin staining (E) and (G) and immunoperoxidase assay with mAb Das-1 (F and H). mAb Das-1 stained both goblet cells (shorter arrow) and metaplastic nongoblet cells (longer arrow) in the glands (F). Intense cytoplasmic staining of the cancer cells with mAb Das-1 is clearly evident in the gastric carcinoma $(H)$ (original magnification 160x).

differences in goblet cell glycoprotein composition. The complete or colonic phenotype appears to carry the highest preneoplastic potential. The colonic phenotype of metaplasia as detected by mAb Das-1 has been reported in stomach, particularly associated with gastric carcinoma. ${ }^{31}$ Ninety-three percent of gastric intestinal metaplasia that stained positive for $\mathrm{mAb}$ Das-1 was associated with gastric cancer. Although normal small intestinal epithelium does not react with $m A b$ Das-1, small intestinal cancer reacts with the antibody. ${ }^{33}$ These findings demonstrate the potential of $\mathrm{mAb}$ Das- 1 antibody to detect preneoplastic changes in the esophagus, stomach, and small intestine.

We rather serendipitously discovered the reactivity of mAb Das-1 against Barrett's epithelium and demonstrated that this antibody reacts with Barrett's epithelium with high sensitivity and specificity. ${ }^{30}$ The reactivity in Barrett's epithelium is present in the goblet cells (GC), as well as in nongoblet cells ${ }^{30}$ in the same glands (Fig. 2B). The reactivity to $\mathrm{mAb}$ Das-1 indicates that the metaplastic change in Barrett's epithelium is of colonic phenotype, includes the entire gland, and is independent of the presence of morphologically evident typical goblet cells. $\mathrm{mAb}$ Das-1 also reacts with $100 \%$ of adenocarcinoma of the esophagus, but does not react with squamous cell carcinoma. ${ }^{30}$

\section{Early detection of columnar metaplasia at the distal esophagus/GEJ in GERD in the absence of histological Barrett's epithelium}

In several studies, we and others demonstrated the presence of mAb Das-1 reactive cells at the distal esophagus in patients with GERD symptoms in the absence of histological Barrett's epithelium. The mAb Das-1 reacted with "cardia-type" columnar epithelium located at the distal esophagus, and not with gastric cardia-epithelium. In one study, $\mathrm{mAb}$ Das-1 reactivity in the IM of the gastroesophageal junction (IM-GEJ) was reported to be $100 \%{ }^{34}$ Following complete histological ablation of Barrett's epithelium by laser therapy, persistence of mAb Das1 reactivity was found to be a better predictor of recurrence. ${ }^{35}$ One hundred percent of cardia-type mucosa reactive to $\mathrm{mAb}$ Das-1 after complete "endoscopic and histologic ablation" of Barrett's epithelium had recurrence of Barrett's epithelium.

We recently completed a prospective study of 262 patients with chronic GERD symptoms who had endoscopy and 4-quadrant biopsies from the distal esophagus/GEJ. Sixteen percent of these patients 

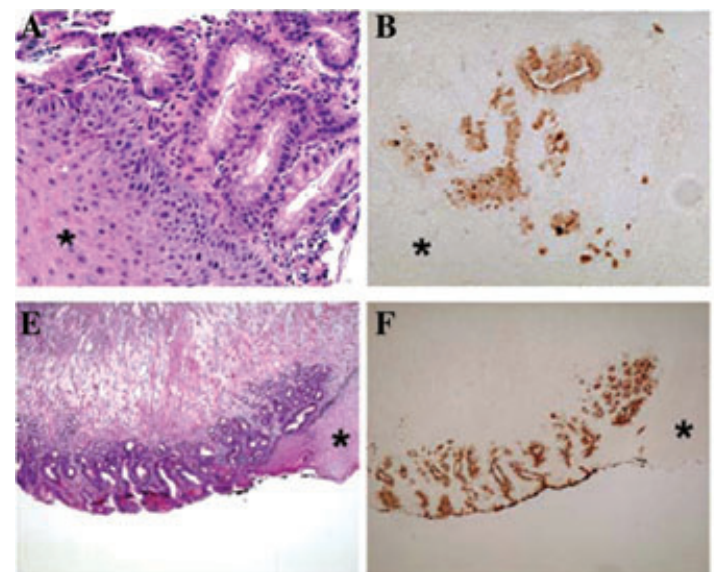
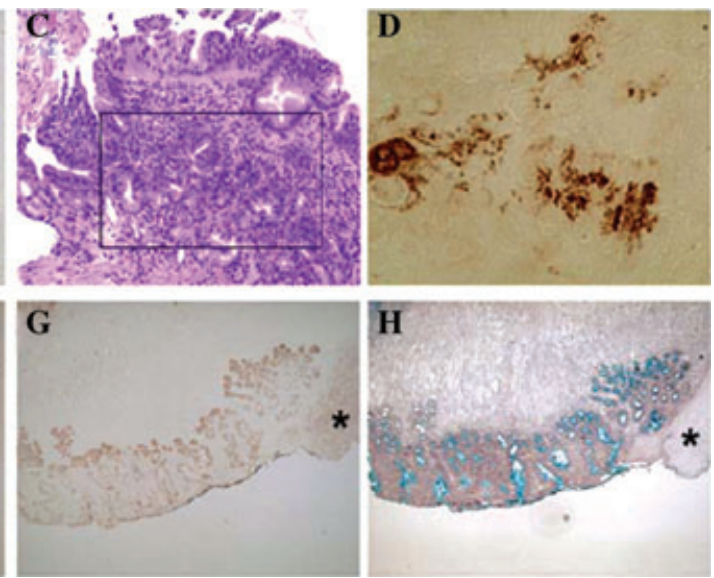

Figure 3. Serial sections of a biopsy specimen from squamo-columnar junction of a patient with initial biopsy that shows mAb Das-1 positive (panel B), but histology with mild esophagitis only (panel A). Panels (C) and (D) show repeat endoscopic biopsy specimen from three-and-a-half years later, showing BE with severe dysplasia (identified by the rectangle). The patient subsequently had endomucosal resection. (E)-(H) show H\&E, mAb Das-1, Cdx-2, and AB/HID stains, respectively. ${ }^{*}$ Indicates squamous epithelium.

with GERD had mAb Das-1 reactivity without histological evidence of Barrett's epithelium/IM. A subset of 11 of these mAb Das -1 positive patients had histological diagnosis of esophagitis $(n=8)$ and three had reportedly normal mucosa. These patients were prospectively followed for up to four years with serial upper endoscopies at one to three year intervals. Of the 11 patients with $\mathrm{mAb}$ Das-1 reactivity in the absence of IM, two developed Barrett's epithelium. One of the two patients that developed Barrett's epithelium subsequently developed Barrett's epithelium with high grade dysplasia after three and a half years (Fig. 3). These data together suggest that metaplasia of colonic phenotype may occur at the distal esophagus in the absence of histological Barrett's epithelium and may progress to Barrett's epithelium. Therefore, mAb Das-1 reactivity may be a useful marker in the identification of $\mathrm{BE}$ at an early stage when chemopreventive strategies may be effective. Immunoperoxidase staining with mAb Das-1 can be performed easily with a serial histologic sections parallel to H\&E.

These in vivo observations are also supported by the novel in vitro model we recently reported. ${ }^{35}$ Exposure of the hTERT transfected, immortalized, benign Barrett's cell line (BAR-T) to HCL (pH4) (A) and bile salt (200 $\mu \mathrm{m}$ glycochenodroxycholic acid) (B) for $5 \mathrm{~min} /$ day for two weeks, BAR-T cells show a two- to threefold increase in colonic phenotype cells that react to mAb Das- $1 .{ }^{36}$ Furthermore, long-term daily exposure (65 weeks) to A + B causes transformation of benign BAR-T cells to neoplastic cells as evident by foci formation, distinct colonies in soft agar and formation of tumor in nude (nu/nu) mice. $^{37}$

\section{What is the frequency of cells showing a similarity with intestinal goblet cells on biopsies and their influence on false diagnosis of Barrett's metaplasia?}

\section{Ana Bennett}

benneta@ccf.org

Not uncommonly, cardiac-type gastric mucosa may contain foveolar cells with barrel-shaped or distended cytoplasmic vacuoles resembling goblet cells. These distended gastric foveolar cells are also called "pseudogoblet" cells and represent a potential source of error in the diagnosis of BE. Fortunately, these mimics usually stain less intensely than true goblet cells with Alcian blue at $\mathrm{pH} 2.5$, and pseudogoblet cells are generally arranged in linear contiguous stretches without intervening columnar cells. ${ }^{38-40}$ Pseudogoblet cells contain a hazy, ground glass appearance to their cytoplasmic mucin (Fig. 4). Esophageal glands and gland ducts are another source of confusion about Alcian bluepositive cells. If they are sampled at all, these glands and ducts are usually located within the deeper 


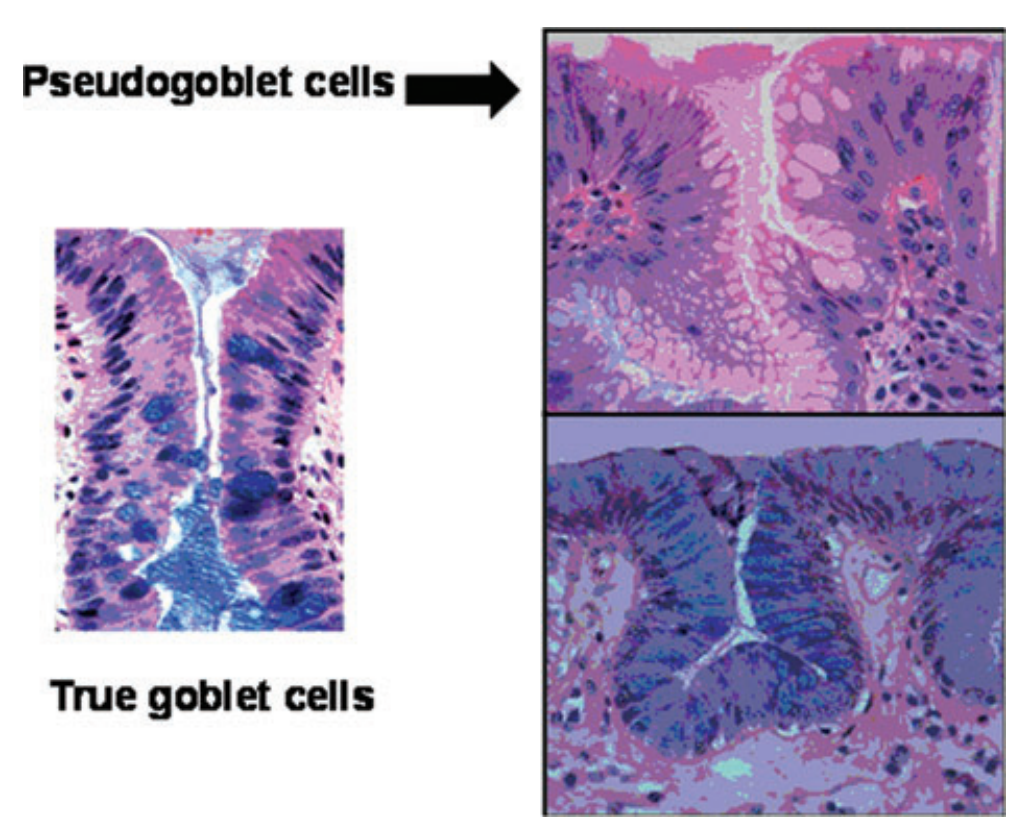

Figure 4. Pseudogoblet cells contain a hazy, ground glass appearance to their cytoplasmic mucin.

portions of endoscopic biopsies in either the lamina propria or submucosa. They are characteristically intensely and diffusely Alcian blue positive at $\mathrm{pH}$ 2.5, but differentiation from true columnar metaplasia is not difficult because esophageal glands have a rounded or lobular configuration similar to minor salivary glands, and are located deep in the mucosa and submucosa. The ducts draining these glands may have a mucinous or transitional-type epithelium and may also contain Alcian blue-positive cells. The contiguous Alcian blue-positive cells within a duct-like structure and/or coexistent transitionaltype epithelium and/or identification of the actual esophageal glands being drained by the duct, usually permit distinction from Barrett's metaplastic epithelium.

A correct diagnosis is essential to spare patients life-long surveillance anxiety and avoid possible inability to obtain medical insurance. Few data are available on the frequency of pseudogoblet cells in esophageal biopsies. In a recent study, ${ }^{41}$ initial biopsies of 78 patients with diagnosis of BE, negative for dysplasia and a mean follow-up of 72 months were reviewed, intestinal-type goblets cells were identified in $56(72 \%)$ of the cases. In the remaining twenty-two cases, only pseudogoblet cells were identified in 12 cases and 10 cases, although originally diagnose as BE did not show either pseudogob- let cells or true goblet cells. Furthermore, only the presence of intestinal-type goblet cells was associated with significant risk of dysplasia $(P=0.008)$. One patient with pseudogoblet cells was diagnosed with dysplasia after 146 months of follow-up compared with $21(35 \%)$ patients with intestinaltype goblet cells that developed dysplasia on follow-up. ${ }^{41}$

It is essential for the pathologist to be aware of the presence of "pseudogoblet" cells or goblet mimickers, which in the absence of true intestinal-type goblet cells do not seem to have a predictive value in neoplastic progression.

\section{Are systematic four-quadrant biopsies the safest way to detect Barrett's epithelium?}

James J. Going

gqxa02@udcf.gla.ac.uk

Paull et al. ${ }^{43}$ described three types of columnar mucosa in Barrett's esophagus (BE), proximal to the lower esophageal sphincter: one resembling gastric fundic mucosa with parietal and chief cells; one resembling gastric cardia mucosa, with mucous glands; and a distinctive type with mucous glands and goblet cells. 


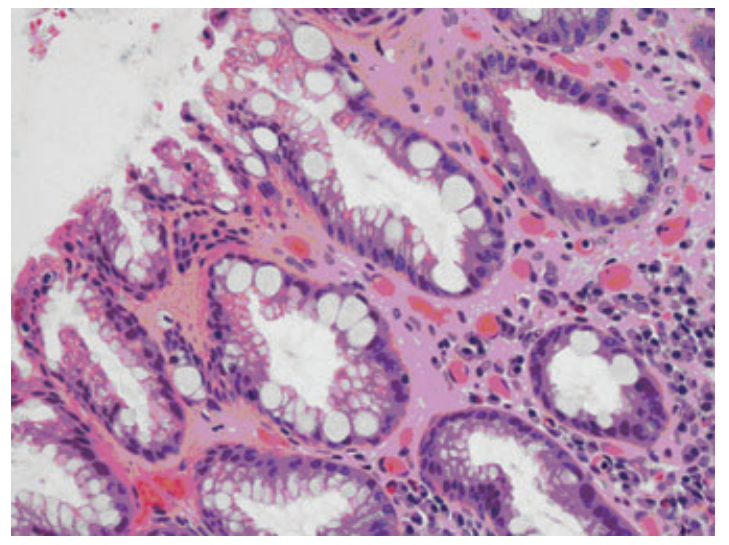

Figure 5. Intestinal metaplasia with goblet cells: until recently, this has been taken as defining feature in Barrett's esophagus. If future work sustains the proposal that cancer risk may be significantly elevated without goblet cells, their importance as a risk marker will diminish.

The answer to the title question depends on whether mucosa with IM defined by goblet cells (IM with GC) is regarded as essential for the diagnosis of $\mathrm{BE}$ (Fig. 5). That IM with goblet cells is essential for a diagnosis of BE has been generally held in the United States and widely, but not universally, in the UK and elsewhere, including Japan. This definition is motivated by the belief in a strong association between IM with goblet cells and dysplasia and increased risk of progression to invasive adenocarcinoma; and that glandular metaplasia alone, in the absence of goblet cells, is not associated with the same elevated cancer risk. After a number of years during which this view has generally been accepted, the evidence for it has begun to be questioned.

Notably, Takubo et al. ${ }^{44}$ describe a weaker than expected association between IM with goblet cells and early Barrett's adenocarcinoma, which appeared in their cases to arise on a background of cardia-like glandular mucosa. In addition, Odze et al. ${ }^{45}$ have pointed out that even in the absence of goblet cells, there may be evidence of intestinal differentiation, including expression of intestinal markers MUC2, DAS1, CDX2, and Villin. Also, recent studies suggest that chromosomal and DNA content abnormalities are not different between metaplastic esophageal glandular mucosa with and without goblet cells, in keeping with a risk of neoplastic progression similar in both.

In the West of Scotland, it is rare for a long segment Barrett's esophagus (LSBE) patient to have no histological IM with goblet cells. ${ }^{46}$ Of thirtytwo randomly selected and systematically biopsied LSBE patients, the cumulative probability of IM being present at any level was about $90 \%$, and $100 \%$ overall. On the other hand, other studies have found a lower prevalence of IM, which may be a function of age.

If the endoscopist thinks there is a long segment Barrett's mucosa, and the histopathologist can demonstrate glandular mucosa in a locus considered to be esophageal by the endoscopist but no IM, often, but not always, the reason will be too few biopsies. For as long as IM with GC is taken to define $\mathrm{BE}$, a minimum of 4-quadrant biopsies will be required before $\mathrm{BE}$ could be excluded. Things are less clear cut in SSBE, but, here too, a 4-quadrant biopsy would be a reasonable diagnostic minimum, except perhaps in the case of an isolated mucosal tongue.

This question is related to whether or not systematic 4-quadrant biopsy is the most effective way to diagnose dysplastic Barrett's mucosa, not Barrett's per se. A (nonrandomized) comparison ${ }^{47}$ of two biopsy approaches at Glasgow Royal Infirmary over nine years began in 1995 when a group of surgeons adopted a systematic biopsy approach, while medical gastroenterologists adhered to nonsystematic protocols. Two demographically similar cohorts each of 180 patients were compared. Prevalance of dysplasia was $18.9 \%$ with systematic biopsy but only $1.6 \%$ with random biopsy. Only $2.2 \%$ of systematically biopsied patients developed incident LGD after a median of 62 months compared with $6.6 \%$ of nonsystematically biopsied patients after a median of 36 months. These data are in keeping with a relatively low incidence of genuinely new dysplasia: most BE patients have had BE for a long time by the time of their index endoscopy. The relatively high prevalence of dysplasia is not unexpected given the high incidence of esophegeal adenocarcinoma in Scotland.

In summary, systematic biopsy appears to be a sound method for identifying IM defined by the presence of goblet cells in columnar-lined esophagus (BE). However, if the definition of $\mathrm{BE}$ is revised to include glandular mucosae without goblet cells, then less comprehensive biopsy strategies may be as effective in establishing the diagnosis; if so, detection of dysplasia (or a validated surrogate risk marker) will be even more important. 


\section{Can the exact role of biomarkers for the diagnosis of BE be defined?}

Mamoun Younes and Helen H. Wang

myounes@bcm.edu

$\mathrm{BE}$, or Barrett's metaplasia, is a condition in which the normal squamous lining of the esophagus is replaced by columnar epithelium. Paul and his colleagues classified $\mathrm{BE}$ on the basis of histologic appearance into three types: cardiac, fundic, and specialized columnar with intestinal type goblet cells. However, only the intestinal type with goblet cells has so far been definitively associated with increased risk of progression to esophageal adenocarcinoma. Currently, in the United States, histologic documentation of intestinal type columnar epithelium with goblet cells is required for the diagnosis of $\mathrm{BE}$.

The diagnosis of $\mathrm{BE}$ is made by identifying intestinal-type goblet cells on routine hematoxylin and eosin (H\&E) stained sections of esophageal biopsies. Several molecular markers have been shown to be expressed in BE by immunohistochemistry (IHC); these include MUC2 ${ }^{48}$ which stains the goblet cells; hepatocyte antigen, ${ }^{49}$ which stains the absorptive cells; villin, ${ }^{50}$ which stains the brush border that incidentally may be lacking in some cases of BE; Das- $1,{ }^{51}$ which stains goblet cells; and CDX $2,{ }^{52}$ which stains cells with intestinal differentiation including goblet and absorptive cells. As expression of these markers was found to correlate very well with "IM" in BE, their clinical utility is limited.

In a few cases, pathologists who may not feel confident making a diagnosis of BE because of a suboptimal H\&E stain, orientation of the biopsy tissue, quality of the section preparation, or presence of rare cells that are equivocal for being intestinaltype goblet cells, the use of biomarkers may help confirm the diagnosis. Problems arise, however, if these markers are applied indiscriminately to all esophageal or esophagogastric junction biopsies endoscopically suspected of being BE. Figure 1 illustrates two such examples. In Figure 6A, IHC for CDX2 shows scattered cells that slightly resemble, but are not typical of full-blown intestinal-type goblet cells (arrows). Here, positive nuclear staining for CDX2 confirms an "intestinal" phenotype. In Figure 6B, none of the columnar epithelial cells at the squamo-columnar junction even slightly resem-

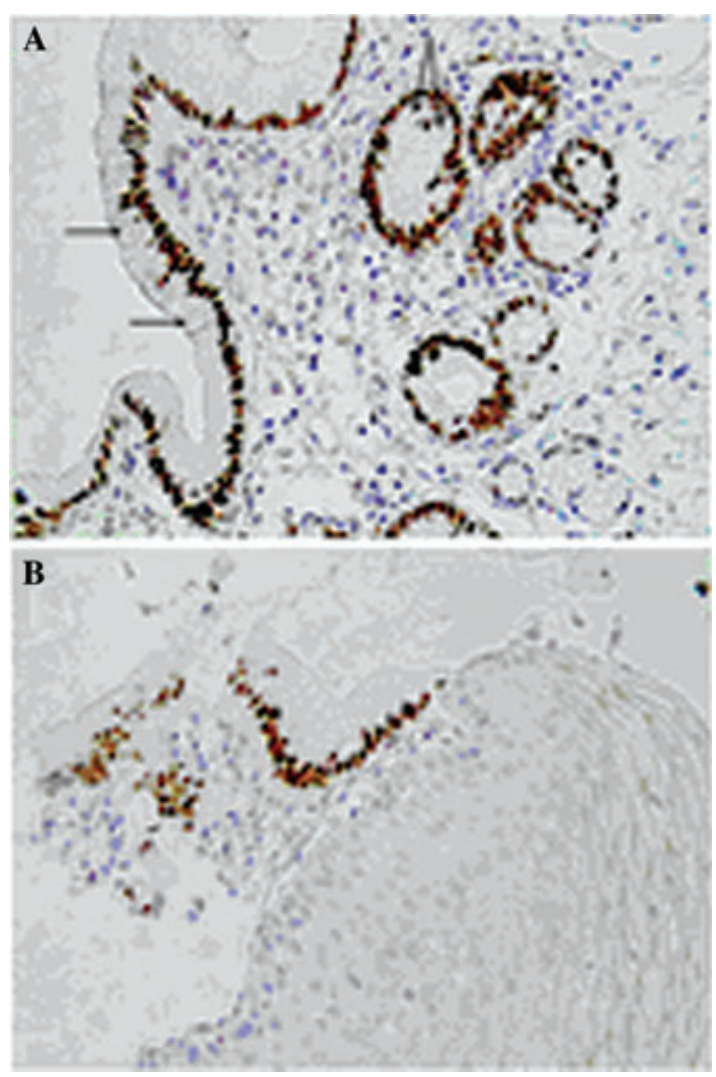

Figure 6. Immunohistochemical staining for CDX2 in biopsies taken from the esophagogastric junction. (A) Positive strong nuclear staining in columnar epithelial cells including cells suspected of being goblet cells (arrows). (B) Strong nuclear staining in columnar cells without any goblet cells or any cells remotely resembling goblet cells. Immunoperoxidase staining with hematoxylin counterstaining, $20 \times$ objective. (Microscope condenser removed for better delineation of cell membranes to demonstrate shapes of cells).

ble goblet cells, yet all of these cells are strongly positive for CDX2. Although these cells may very well be "pregoblets" and may, with time, become goblet cells, this is just speculative at the present time. Almost all patients who have esophageal biopsies to rule out $\mathrm{BE}$ are symptomatic, and do receive treatment, medical or surgical, for GERD. Therefore, it will be extremely difficult to know the natural history of CDX2 biopsies without goblets, as this will be altered by intervention (medical or surgical), and one would expect that since reflux is thought to be the cause of CDX2 expression, adequate treating of GERD, at least in theory, should reverse CDX2 expression or should 
prevent the CDX2-positive cells from progressing to a goblet phenotype. "Reversal" of established $\mathrm{BE}$ with goblet cells with medical treatment has been reported. In one study, CDX2 expression in biopsies of columnar-lined esophagus without goblet cells was found to predict the finding of goblet cells in a second set of biopsies from the same patients (taken either before or after the CDX2positive biopsies). ${ }^{53}$ In the same study, however, $24 \%$ of patients with CDX2-positive biopsies without goblet cells had no goblet cells in a second set of biopsies. ${ }^{53}$ Because patients with $\mathrm{BE}$ are subjected to life-long surveillance and biopsy, anxiety about their increased chances of getting esophageal cancer, cost, and adverse effects of some modalities to treating or eradicating BE, and increased health and life insurance premiums, and because most follow-up studies so far have shown no significant association between columnar-lined epithelium without goblet cells and esophageal cancer, strong evidence of association between CDX2-positive nongoblet cell CLE and esophageal cancer from large-scale prospective studies is required before labeling these patients as having $\mathrm{BE}$.

\section{What is the value of molecular markers (CDX2, MUC2, and CK7/20) for identification of patients predisposed to the development of BE?}

Antonio Taddei, Giancarlo Freschi, Maria Novella Ringressi, Duccio Rossi Degli'Innocenti, Francesca Castiglione, and Paolo Bechi antonio.taddei@unifi.it

Homeobox protein CDX2 is encoded by the CDX2 gene. In humans, this protein is a caudal homeobox transcription factor, which is involved in the modulation of complex signaling pathways and transcription processes, important both for embryonic development and the homeostasis of adult tissues. Although CDX2 role in BE is not completely understood, it is noticeable that CDX2 is not expressed in the normal squamous esophageal epithelium, whereas it has been shown to be highly expressed in $\mathrm{BE}^{54}$

Mucins are also widely secreted in the gastrointestinal tract, with distinct composition patterns in the different locations. Among mucins, mucin 2 (MUC2) is prominent in the gut, where it is mainly

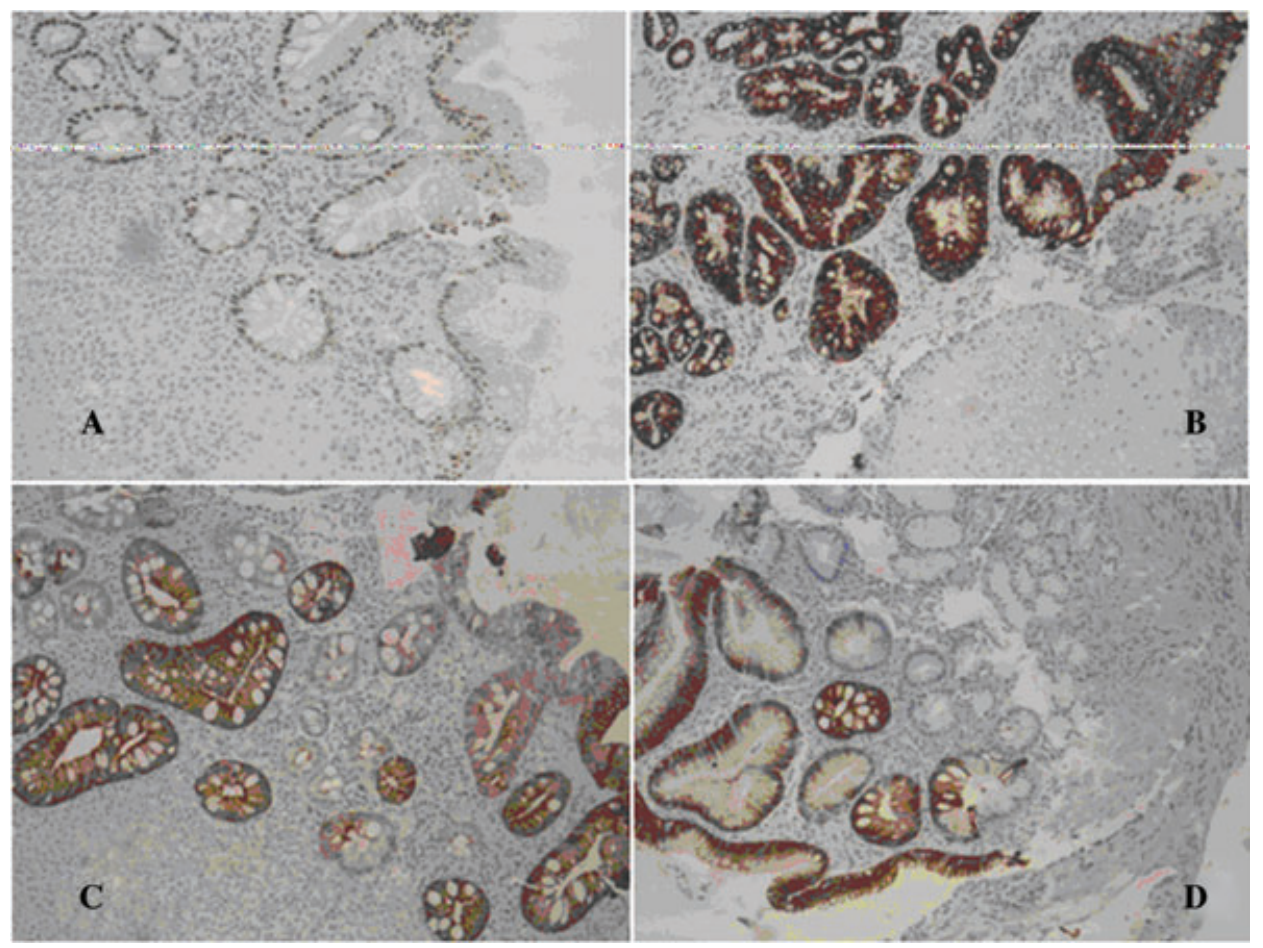

Figure 7. Preliminary data showing expression of CDX2 (A), MUC-2 (B), CK7 (C) and CK20 (D) in BE subjects (see text on p. 12 in question 11). 
secreted from goblet cells of the epithelial lining into the lumen of the large intestine. ${ }^{55}$

Cytokeratins (CK) form the building blocks for the intermediate filaments, which contribute to cell cytoskeleton formation. There are variable patterns of expression of cytokeratins in epithelial cells depending on the type, location, and differentiation of epithelium. CK7/20 profiles are considered relevant for the diagnosis of some diseases of the gastrointestinal tract. CK20 is commonly used as a marker of intestinal differentiation. It is widely expressed on the surface and crypt epithelium of the normal colon and small intestine. In the stomach, its expression is limited to the surface foveolar epithelium (no gastric gland/pit expression). In the esophagus, CK7 specific staining is only detectable in the superficial layers of the squamous epithelium, whereas in columnar metaplasia, increased expression is shown more deeply throughout the crypts and the glands.

It has been claimed that a specific staining pattern reliably distinguishes intestinal from the cardial and oxyntic metaplasia. ${ }^{56}$ This so-called Barrett's pattern is characterized by CK20 superficial staining and diffuse and strong CK7 staining and has been demonstrated both in long and short segment BE. ${ }^{56}$ More recently, the presence of a CK7/20 Barrett's pattern has been confirmed, its presence in ultrashort segment $\mathrm{BE}$ has been demonstrated. ${ }^{57}$

We have preliminary data showing indicating that CDX2 was absent in all the patients both of normal epithelium and the esophagitis groups (unpublished data). On the contrary, it was highly expressed in BE: in this group of biopsies a strong nuclear staining was observed (Fig. 7A). MUC2 had exactly the same behavior, it was absent both in normal epithelium and in the esophagitis groups, whereas it was well expressed in BE: in this group of biopsies a strong cytoplasmatic staining was shown (Fig. 7B). CK7 and $\mathrm{Ck} 20$ expression showed a distribution that differed from CDX2 and MUC2; their expression (similar for CK7 and CK20) was evident in all three groups patients. However, their expression was significantly $(P=0.023)$ greater in $\mathrm{BE}$ than in normal epithelium and esophagitis groups (Fig. 7C \& 7D, respectively). It must be stressed that none of the patients in the group with CK7/20 expression developed BE after a five-year follow-up (unpublished data).
In conclusion, although CDX2 and MUC2 are both a definite marker of IM, they cannot be used to identify the patients at risk of BE, since they do not seem to be expressed in any of the patients earlier steps of reflux disease. Moreover, CK7/20 in spite of increased expression in BE than in normal epithelium and esophagitis, do not seem to identify those patients who will develop BE. Therefore, on the basis of this preliminary experience, this panel of immunohystochemical markers, seems certainly useful for BE identification but not to predict its occurrence.

\section{Conflicts of interest}

The authors declare no conflicts of interest.

\section{References}

1. Wang, K.K. \& R.E. Sampliner. 2008. Practice Parameters Committee of the American College of Gastroenterology. Updated guidelines 2008 for the diagnosis, surveillance and therapy of Barrett's oesophagus. Am. J. Gastroenterol. 103: 788-797.

2. Barr, H. \& N.A. Shepherd. The management of dysplasia. Guidelines for the diagnosis and management of Barrett's columnar-lined oesophagus: a report of the working Party of the British Society of Gastroenterology August 2005. Available at: http://www.bsg.org.uk.

3. Liu, W., H. Hejin Hahn, R.D. Odze \& R.K. Goyal. 2009. Metaplastic esophageal columnar epithelium without goblet cells shows DNA content abnormalities similar to goblet cell containing epithelium. Am. J. Gastroenterol. 104: 816-824.

4. Kelty, C., M. Gough \& Q. Van Wyk. 2007. Barrett's oesophagus: intestinal metaplasia is not essential for cancer risk. Scand. J. Gastroenterol. 42: 1271-1274.

5. Gatenby, P.A., J.R. Ramus, C.P. Caygill, et al. 2008. Relevance of the detection of intestinal metaplasia in non-dysplastic columnar-lined oesophagus. Scan. J. Gastroenterol. 43: 524530 .

6. Takubo, K., K. Sasa, K. Yamashita, et al. 1991. Double muscularis mucosae in Barrett esophagus. Hum. Pathol. 22: 11581161.

7. Srivastava, A., R.D. Odze, G.Y. Lauwers, et al. 2007. Morphologic features are useful in distinguishing Barrett esophagus from carditis with intestinal metaplasia. Am. J. Surg. Pathol. 31: 1733-1741.

8. Ormsby, A.H., J.R. Goldblum, T.W. Rice, et al. 1999. Cytokeratin subsets can reliably distinguish Barrett's esophagus from intestinal metaplasia of the stomach. Hum. Pathol. 30: 288-294.

9. Nurgalieva, Z., A. Lowrey \& H.B. El-Serag. 2007. The use of cytokeratin stain to distinguish Barrett's esophagus from contiguous tissues: a systematic review. Dig. Dis. Sci. 52: 1345-1354.

10. Odze, R.D. 2005. Unraveling the mystery of the gastroesophageal junction: a pathologist's perspective. Am. J. Gastroenterol. 100: 1853-1867. 
11. Su, Y., X. Chen, M. Klein, et al. 2004. Phenotype of columnarlined esophagus in rats with esophagogastroduodenal anastomosis: similarity to human Barrett's esophagus. Lab. Invest. 84: 753-765.

12. Orlando, R.C. 2006. Mucosal defense in Barrett's esophagus. In Barrett's Esophagus and Esophageal Adenocarcinoma. Sharma P. and Sampliner R., pp 60-72. Ed. Blackwell Publishing. Malden.

13. Long, J.D. \& R.C. Orlando. 1999. Esophageal submucosal glands: structure and function. Am. J. Gastroenterol. 94: 2818-2824.

14. Li, H., T.N. Walsh, G. O'dowd, et al. 1994. Mechanisms of columnar metaplasia and squamous regeneration in experimental Barrett's esophagus. Surgery 115: 176-181.

15. Gillen, P., P. Keeling, P.J. Byrne, et al. 1988. Implication of duodenogastric reflux in the pathogenesis of Barrett's oesophagus. Br. J. Surg. 75: 540-543.

16. Vakil, N., S.V. van Zanten, P. Kahrilas, et al.; the Global Consensus Group. 2006. The Montreal definition and classification of gastroesophageal reflux disease: a global evidence-based consensus. Am. J. Gastroenterol. 101: 19001920.

17. Sharma, P., J. Dent, D. Armstrong, et al. 2006. The development and validation of an endoscopic grading system for Barrett's esophagus: the Prague C and M criteria. Gastroenterology 131: 1392-1399.

18. Amano, Y., N. Ishimura, K. Furuta, et al. 2006. Which landmark results in a more consistent diagnosis of Barrett's esophagus, the gastric folds or the palisade vessels? Gastrointest. Endosc. 64: 206-211.

19. Riddell, R.H., V. Mann, P. Moayyedi, et al. 2006. Targeted esophageal biopsies: what you see is what you get (WYSIWYG) —or not? Gastroenterology 130: A161 (Abstract S1139).

20. De Hertogh, G., P. Van Eyken, N. Ectors, et al. 2003. On the existence and location of cardiac mucosa: an autopsy study in embryos, fetuses, and infants. Gut 52: 791-762.

21. Chandrasoma, P. 2005. Controversies of the cardiac mucosa and Barrett's oesophagus. Histopathology 46: 361-73.

22. Peitz, U., M. Vieth, M. Pross, et al. 2004. Cardia-type metaplasia arising in the remnant esophagus after cardia resection. Gastrointest. Endosc. 59: 810-817.

23. Hattori, T., K. Mukaisho \& K. Miwa. 2005. Pathogenesis of Barrett's esophagus - new findings in the experimental studies of duodenal reflux models. Nippon Rinsho. 63: 13411349.

24. Vieth, M. \& H. Barr. 2009. Defining a bad Barrett's segment: is it dependent on goblet cells? Am. J. Gastroenterol. 104: 825-874.

25. Liu, W., H. Hahn, R.D. Odze \& R.K. Goyal. 2009. Metaplastic esophageal columnar epithelium without goblet cells shows DNA content abnormalities similar to goblet cell-containing epithelium. Am. J. Gastroenterol. 104: 816-824.

26. Stein, H.J., M. Feith \& H. Feussner. 2000. The relationship between gastroesophageal reflux, intestinal metaplasia and adenocarcinoma of the esophagus. Langenbeck's Arch. Surg. 385: 309-316.

27. Siewert, J.R., M. Feith, M. Werner \& H. Stein. 2000. Adenocarcinoma of the esophagogastric junction: results of surgi- cal therapy based on anantomical/topographic classification in 1,002 consecutive patients. Ann. Surg. 232: 353-361.

28. Gangarosa, L., S. Halter \& H. Mertz. 1999. Dysplastic gastroesophageal junction nodules-a precursor to junctional adenocarcinoma. Am. J. Gastroenterol. 94: 835-838.

29. Tytgat, G.N.J., J.W. van Sandick, J.J.B. van Lanschot \& H. Obertop. 2003. Role of Surveillance in Intestinal Metaplasia of the Esophagus and Gastroesophageal Junction. World J. Surg 27: 1021-1025.

30. Das, K.M., I. Prasad, S. Garla \& P.S. Amenta. 1994. Detection of a shared colon epithelial epitope on Barrett epithelium by a novel monoclonal antibody. Ann. Intern. Med. 120: 753 756

31. Mirza, Z.K., K.K. Das, R.N. Mapitigama, et al. 2003. Gastric intestinal metaplasia as detected by a novel biomarker is highly associated with gastric adenocarcinoma. Gut 52: 807812 .

32. Das, K.M., S. Sakamaki, M. Vecchi \& B. Diamond. 1987. The production and characterization of monoclonal antibodies to a human colonic antigen associated with ulcerative colitis: cellular localization of the antigen using the monoclonal antibody. J. Immunol. 139: 77-84.

33. Onuma, E.K., P.S. Amenta, A.F. Jukkola, et al. 2001. A phenotypic change of small intestinal epithelium to colonocytes in small intestinal adenomas and adenocarcinomas. Am. J. Gastroenterol. 96: 2480-2485.

34. Glickman, J.N., H. Wang, K.M. Das, et al. 2001. Phenotype of Barrett's esophagus and intestinal metaplasia of the distal esophagus and gastroesophageal junction: an immunohistochemical study of cytokeratins 7 and 20, Das-1 and $45 \mathrm{MI}$. Am. J. Surg. Pathol. 25: 87-94.

35. Fisher, R.S., M.Q. Bromer, R.M. Thomas, et al. 2003. Predictors of recurrent specialized intestinal metaplasia after complete laser ablation. Am. J. Gastroenterol. 98: 1945-1951.

36. Bajpai, M., J. Liu, X. Geng, et al. 2008. Repeated exposure to acid and bile selectively induces colonic phenotype expression in a heterogeneous Barrett's epithelial cell line. Lab. Invest. 88: 643-651.

37. Das, K.M., Y. Kong, M. Bajpai, et al. 2011. Transformation of benign Barrett's epithelium by repeated acid and bile exposure over 65 weeks: a novel in-vitro model. Int. J. Cancer 128: $274-282$.

38. Weinstein, W.M. \& A.F. Ippoliti. 1996. The diagnosis of Barrett's esophagus: goblets, goblets, goblets. Gastrointest. Endosc. 44: 91-95.

39. Offner, F.A., K.J. Lewin \& W.M. Weinstein. 1996. Metaplastic columnar cells in Barrett's esophagus: a common and neglected cell type. Hum. Pathol. 27: 885-889.

40. Chen, Y-Y, H. Wang, D.A. Antonioli, et al. 1999. Significance of acid-mucin-positive on goblet columnar cells in the distal esophagus and gastroesophageal junction. Hum. Pathol. 30: 1488-1495.

41. Younes, M., A. Ertan, G. Ergun, et al. Goblet cell mimickers in esophageal biopsies are not associated with an increased risk for dysplasia. Arch. Pathol. Lab. Med. 131: 571575.

42. Paull, A., J.S. Trier, M.C. Dalton, et al. 1976. The histologic spectrum of Barrett's esophagus. N. Engl. J. Med. 295: 476480. 
43. Takubo, K., J. Aida, Y. Naomoto, et al. 2009. Cardiac rather than intestinal-type bacgkground in endoscopic resection specimens of minute Barrett adenocarcinoma. Hum. Pathol. 40: 65-74.

44. Hahn, H.P., P.L. Blount, K. Ayub, et al. 2009. Intestinal differentiation in metaplastic, non-goblet columnar epithelium in the oesophagus. Am. J. Surg. Pathol. 33: 10061015.

45. Going, J.J., A.J. Fletcher-Monaghan, L. Neilson, et al. 2004. Zoning of mucosal phenotype, dysplasia and telomerase measured by telomerase repeat assay protocol (TRAP) in Barrett's esophagus. Neoplasia 6: 85-92.

46. Abela, Jo-Etienne, James J. Going, John F. Mackenzie, et al. 2008. Systematic four-quadrant biopsy detects Barrett's dysplasia in more patients than nonsystematic biopsy. Am. J. Gastroenterol. 103: 850-855.

47. Endo, T., K. Tamaki, Y. Arimura, et al. 1998. Expression of sulfated carbohydrate chain and core peptides of mucin detected by monoclonal antibodies in Barrett's esophagus and esophageal adenocarcinoma. J. Gastroenterol. 33: 811815.

48. Chu, P.G., Z. Jiang \& L.M. Weiss. 2003. Hepatocyte antigen as a marker of intestinal metaplasia. Am. J. Surg. Pathol. 27: 952-959.

49. Kumble, S., M.B. Omary, L.F. Fajardo \& G. Triadafilopoulos. 1996. Multifocal heterogeneity in villin and Ep-CAM expression in Barrett's esophagus. Int. J. Cancer 28: 48-54.

50. Glickman, J.N., H. Wang, K.M. Das, et al. 2001. Phenotype of Barrett's esophagus and intestinal metaplasia of the distal esophagus and gastroesophageal junction: an immunohistochemical study of cytokeratins 7 and 20, Das-1 and $45 \mathrm{MI}$. Am. J. Surg. Pathol. 25: 87-94.

51. Eda, A., H. Osawa, K. Satoh, et al. 2003. Aberrant expression of CDX2 in Barrett's epithelium and inflammatory esophageal mucosa. J. Gastroenterol. 38: 14-22.

52. Kerkhof, M., D.A. Bax, L.M. Moons, et al. 2006. Does CDX2 expression predict Barrett's metaplasia in oesophageal columnar epithelium without goblet cells? Aliment Pharmacol. Ther. 24: 1613-1621.

53. Souza, R.F., K. Krishnan \& J.S. Spechler, 2008. Acid, Bile, and CDX: the ABCs of making Barrett's metaplasia. Am. J. Physiol. Gastrointest. Liver Physiol. 295: 211-218.

54. Gulmann, C., O.L. Shaqaqi, A. Grace, et al. 2004. Cytokeratin $7 / 20$ and MUC1, 2, 5AC, and 6 expression patterns in Barrett's esophagus and intestinal metaplasia of the stomach. Appl. Immunohistochem. Mol. Morphol. 12: 142147.

55. Ormsby, A.H., J.R. Goldblum \& T.W. Rice. 1999. Citokeratyn subset can reliably distinguish Barrett's esophagus from Intestinal Metaplasia of the stomach. Hum. Pathol. 30: 288294.

56. Couvelard, A., J.M. Cauvin, D. Goldfain, et al. 2001. Cytokeratin immunoreactivity of intestinal metaplasia at normal oesophagogastric junction indicates its aetiology. Gut 49: 761-766.

57. Steininger, H., D.A. Pfofe, H. Müller, et al. 2005. Expression of CDX2 and MUC2 in Barrett's mucosa. Pathol. Res. Pract. 201: 573-577. 